\title{
Deformation-Induced Mechanical Instabilities at the Core-Mantle Boundary
}

\author{
N. Petford \\ Bournemouth University, Fern Barrow, Poole, Dorset, UK \\ T. Rushmer \\ Department of Earth and Planetary Sciences, GEMOC, Macquarie University, Sydney, New South Wales, Australia \\ D.A. Yuen \\ Minnesota Supercomputer Institute, University of Minnesota, Minneapolis, Minnesota, USA
}

Our understanding of the core-mantle boundary (CMB) region has improved significantly over the past several years due, in part, to the discovery of the postperovskite phase. Sesimic data suggest that the CMB region is highly heterogeneous, possibly reflecting chemical and physical interaction between outer core material and the lowermost mantle. In this contribution we present the results of a new mechanism of mass transfer across the CMB and comment on possible repercussions that include the initiation of deep, siderophile-enriched mantle plumes. We view the nature of core-mantle interaction, and the geodynamic and geochemical ramifications, as multiscale processes, both spatially and temporally. Three lengthscales are defined. On the microscale $(1-50 \mathrm{~km})$, we describe the effect of loading and subsequent shearing of the $\mathrm{CMB}$ region and show how this may drive local flow of outer core fluid upwards into $\mathrm{D}^{\prime \prime}$. We propose that larger scale processes operating on a mesoscale $(50-300 \mathrm{~km})$ and macroscale regimes $(>300 \mathrm{~km})$ are linked to the microscale, and suggest ways in which these processes may impact on global mantle dynamics.

\section{INTRODUCTION}

The boundary between the lowermost mantle and outer core, including the $\mathrm{D}^{\prime \prime}$ bottom layer, is the most active region of the Earth's deep interior. Our understanding of the core-mantle boundary $(\mathrm{CMB})$ region has improved significantly over the past several years due to a combination of improvements in

Post-Perovskite: The Last Mantle Phase Transition Geophysical Monograph Series 174

Copyright 2007 by the American Geophysical Union 10.1029/174GM18 seismic resolution and the recent discovery in 2004 of the post-perovskite (ppv) phase (Murakami et al., 2004; Tsuchiya et al, 2004; Ono and Oganov, 2004, Mao et. al., 2004). The perovskite (pv) to post-perovskite (ppv) phase transition near the $\mathrm{CMB}$, as revealed from from experiments and calculations, has exciting and potentially far-reaching consequences (Monnereau and Yuen, 2007). It is already clear that this transition can profoundly influence the dynamics of the $\mathrm{D}^{\prime \prime}$ layer, and by implication, the CMB (Nakagawa and Tackley, 2004; 2006; Lay et al., 2004, Hernlund et al., 2005; Matyska and Yuen, 2005, 2006; Petford, 2006; Yuen et al., 2007). Furthermore, the elastic properties of post-perovskite are quite different from 
perovskite, a factor that may account for much of the seismic anisotropy in $\mathrm{D}^{\prime \prime}$ (Lay et al., 2004).Yet despite this progress, the extent to which the seismic properties of the lower mantle relate to the phase transition alone, or other processes including material transfer of outer core fluid across the $\mathrm{CMB}$ and into $\mathrm{D}^{\prime \prime}$, remain unclear. Less controversially, heat transfer across the core-mantle boundary (CMB) is fundamental in generating large scale instabilities including plume and superplume upwellings which impact not just on the lower mantle but the whole earth system (Davies, 1999; Gibbons and Gubbins, 2000; Olson, 2003; Boyet and Carlson, 2005, Nolet et al., 2006). Thus, identifying the mode and extent to which the Earth's silicate lowermost mantle and liquid outer core have interacted physically over geological time has far-reaching consequences for mantle dynamics, plume initiation and fluxes and the long-term geochemical evolution of the mantle (e.g Sleep, 1990; Romanowicz and Gung, 2002; Brandon and Walker, 2005; Nolet et al., 2006).

Seismically, the lowermost 200-300 km of Earth's mantle is anomalous. Geophysical investigations over the last decade show that $\mathrm{D}^{\prime \prime}$, the $\sim 100-350 \mathrm{~km}$-thick seismic layer located near the $\mathrm{CMB}$ and characterized generally by a negative shear velocity and small compressional velocity gradients, is both seismically heterogeneous and anisotropic on vertical and horizontal length scales down to c. $10 \mathrm{~km}$ (e.g. Garnero 2000, Wang and Wen, 2004). Seismic studies have also revealed several hundred meters of small-scale topography on the core-mantle boundary (e.g Earle and Shearer, 1997). In addition, a thin layer at the base of the mantle where compressional wave velocities drop by $\sim 10 \%$ (Ultra Low Velocity Zone) may contain $\sim 5-30 \%$ partial melt (Williams and Garnero, 1996, Garnero, 2000; Lay et al., 2004). But D" is not only a thermal and chemical boundary layer. The region is also a mechanical boundary layer susceptible to regionalscale deformation deformaton (Karato, 1998 a,b; McNamara et al. 2002; Panning and Romanowicz, 2004, Merkel et al., 2007). The strain-field measured by seismic methods has revealed a detectable anisotropy due to the alignment of crystals or lateral changes in material (elastic) properties (Karato, 1998a,b; Panning and Romanowicz, 2004), while numerical simulations show that large strain deformations accumulate in high stress zones associated with downwelling material (McNamara et al., 2002). Most recently, Merkel et al (2007) have proposed that structural features such as mechanical layering, in addition to the elastic properties of post-perovskite, may be needed to explain seismic anisotropy in $\mathrm{D}^{\prime \prime}$.

In tandem with these new developments in mineral physics and seismology, recent geochemical evidence implies that some deep mantle plumes originating at the core-mantle boundary (e.g. Montelli et al., 2004) may have tapped a D" source region modified by core-mantle interaction. Although unique geochemical identifiers appear lacking, recent osmium isotopic studies of plume-derived materials
(Brandon et al., 2003; Brandon and Walker, 2005), combined with Fe/Mn ratios in Hawaiian lavas (Humayun et al., 2004), suggest that putative CMB-derived plumes may have sampled $\sim 0.5 \%$ core material, inherited from a thermal or Feenriched chemical boundary layer at the core-mantle interface (Humayun, et al., 2004).

In this contribution, we combine the results of mineral physics calculations on the elastic properties of postperovskite with deformation modeling of viscoelastic media, deformation experiments, geochemistry and other geophysical information (such as geoid constraints) to build an integrated model of the geodynamic behavior of $\mathrm{D}^{\prime \prime}$. We argue that the dynamics of the lower mantle can be understood in terms of three interlinked, hierarchical processes that begin at the grain scale and culminate with the generation of chemically-enriched mantle plumes. At the smallest scale (defined here as the microscale), local deformation of the $\mathrm{CMB}$ region is the chief agent responsible for imparting chemical heterogeneity in $\mathrm{D}^{\prime \prime}$. The mesoscale regime $(50-300 \mathrm{~km})$ is characterized by internal boundary layer flow and small scale convection within this sub-layer. Finally, the macroscale regime $(300-1000 \mathrm{~km})$ is treated as a lower mantle convection problem.

\section{APPROACH}

We view lower mantle geodynamics as a multiscale system, both spatially and temporally. In this sense we have taken a lead from other disciplines in geophysical fluid dynamics, notably meteorology, where small-scale perturbations are known to impact significantly on global circulation patterns. Fig. 1 shows how the relevant length scales interact with each other, highlighting in particular how macroscale processes help drive microscale fluid flow and core-mantle chemical interaction by generating the required deformation field. Fig. 1 provides a roadmap of how we think the various linkages between the physical properties of the postpervoskite phase, geochemistry, deformation and mantle dynamics may operate. These linkages are summarized qualitatively in cartoon form in Fig. 2.

In the following sections we look in more detail at the specific, scale-dependent processes that underpin our geodynamic model. The microscale modeling is informed from knowledge of the elastic properties of the post-perovskite phase derived from ab-initio molecular dynamic simulations (Stackhouse et al., 2005). Deformation experiments on metal-silicate systems and simulations to determine the effects of radiative heat transfer in $\mathrm{D}^{\prime \prime}$ are also important components of the microscale model, the latter providing a potentially important upscaling route to superplume nucleation at the CMB. We end by discussing the implications of our model for core-mantle boundary initiation of plumes and global mantle evolution. 


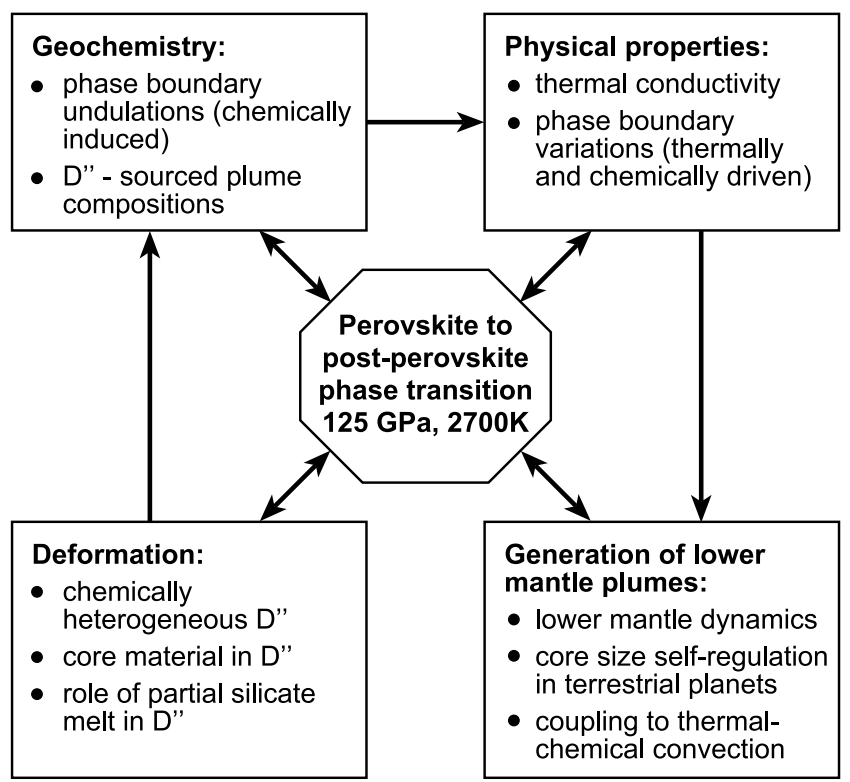

Figure 1. Flowchart summarizing the links between the four key components underpinning the geodynamical evolution of the lower mantle (physical properties, deformation, geochemistry and plume generation), and their relationship with the post-perovskite phase transition.

\section{MICROSCALE PROCESSES: DEFORMATION- DRIVEN MASS TRANSFER ACROSS THE CMB}

In this section we address the physical mechanism responsible for locally transporting liquid metal from the outer core across the CMB into $\mathrm{D}^{\prime \prime}$. Identifying a physical processes capable of transporting liquid metal upwards across the CMB remains challenging. Put simply, density arguments make physically emplacing outer core material into D" via buoyancy fluxing problematic (Stevenson, 2003; Kandar and Stevenson, 2006). Indeed, there is a reverse analogy with fluid dynamic models of core formation (e.g. Stevenson, 1990). The high density of liquid metal compared to mantle silicates means that buoyancy forces dominate the transport processes, which is essentially one of drainage. From this perspective, upwelling of liquid metal by gravity-driven instabilities back into the lower mantle makes little sense. In an attempt to overcome this contradiction, Petford et al., (2005a) proposed a possible mechanism for upwards transport of dense liquid metal that involves shear-aided dilation of mantle silicate grains in the vicinity mantle downwellings. Dilatancy of the type first described by Reynolds (1885) is commonly observed in tests on granular materials under low stress (low in the sense that the elastic moduli of individual

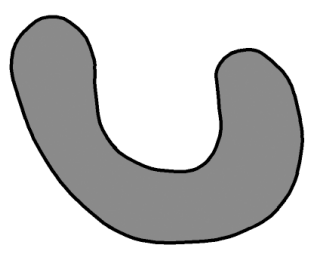

\section{Lower mantle}

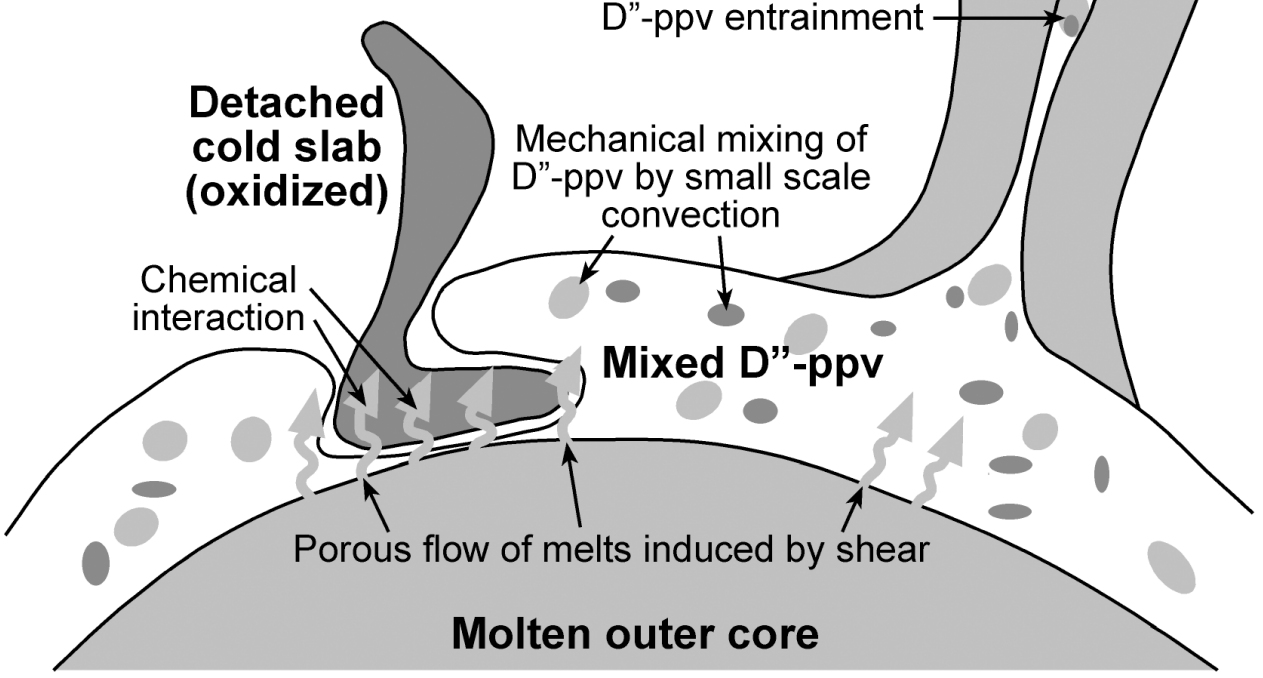

Figure 2. Cartoon summarizing some of the physical processes and geometries identified in Fig. 1 along with a qualitative indication of the governing lengthscales. 
grains are small compared with the overall skeleton stress, ensuring that the constituents of the solid framework remain virtually undeformed). Dilatancy differs fundamentally from compaction, where pore space is destroyed due to viscous deformation of the grains comprising the matrix (McKenzie, 1984; Buffett et al., 2000). The idea put forward is that Reynolds dilatancy could, given an appropriate matrix rheology, play a role in 'sucking' core material upwards across the $\mathrm{CMB}$, thus contributing to some of the chemical and geophysical variability observed in $\mathrm{D}^{\prime \prime}$. This concept is explored in more detail below.

\subsection{Shear-Aided Dilatancy}

For shear-aided dilation to occur, $\mathrm{D}^{\prime \prime}$ must be deformed by one or more mechanisms so that the required stresses are generated. We emphasize that with the exception of the pvppv phase transition, the potential driving mechanisms outlined below are likely to be both local and discrete in space and time. In our calculations, loading of the CMB by cold downwelling mantle is the main deformation mechanism (Fig 4). The deformational and rheological consequences of cold material impacting on the CMB have been described by Karato (1998a,b), who identified regions characterised by both simple and pure shear (Fig. 3a,b). Following theory outlined by Petford et al., (2005 a,b); and Koenders and Petford, (2003, 2005), predicting the effects of externally derived shearing forces in granular media, we present order of magnitude estimates of the upwelling fluid flow and mass flux rates of core liquid metal across the $\mathrm{CMB}$ in the vicinity of the shear field set up by the impacting slab (Fig. 4). The instability follows thus. A typical value for the liquid (outer core) viscosity is $10^{-2} \mathrm{~Pa} \mathrm{~s}$ (Secco et al., 1998), the length scale $H$ is assumed to be $10 \mathrm{~km}$ (Garnero, 2000). The permeability is obtained from the well-known Kozeny-Carman relationship with an assumed mean ppv grain size of $10^{-3} \mathrm{~m}$ and a local porosity (silicate melt fraction) of 0.2-0.4 (see Williams and Garnero, 1998; Ohtani and Maeda, 2001; Lay et al., 2004, Rost et al., 2005; Petford et al., 2005). Note that the assumed presence of a silicate melt fraction at the CMB is critical for our model as the dilatancy effect (local volume increase) will not work without some pre-existing pore space. The required porosity is a silicate melt fraction that will be displaced or intermix with upwelling metallic fluid (e.g. Garnero, 2000). An important feature of the model is that from the perspective of strain rate-sensitive media, upwelling velocities velocity scales linearly with the rate of deformation (see Koenders and Petford, 2000; Petford and Koenders, 2003; Petford et al., 2005a), thus overcoming textural problems relating to percolation of Fe-rich melts through a silicate matrix constrained by high dihedral angles (e.g. Bruhn et al., 2000; Rushmer et al., 2000). A key parameter

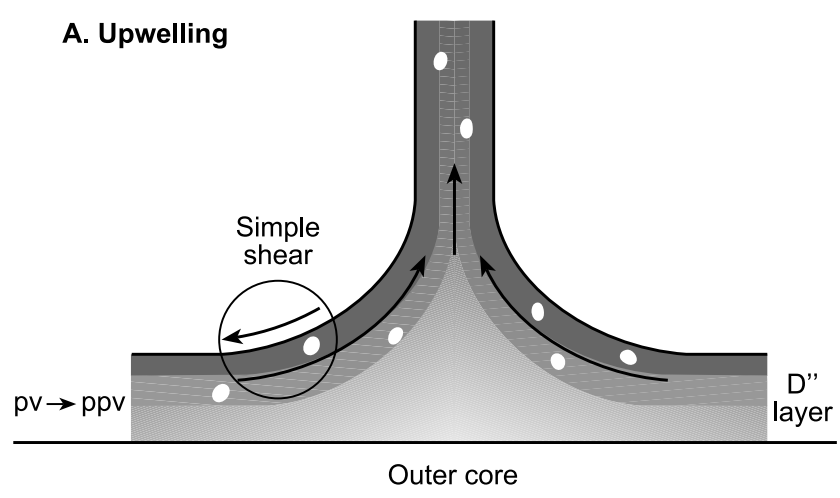

B. Downwelling

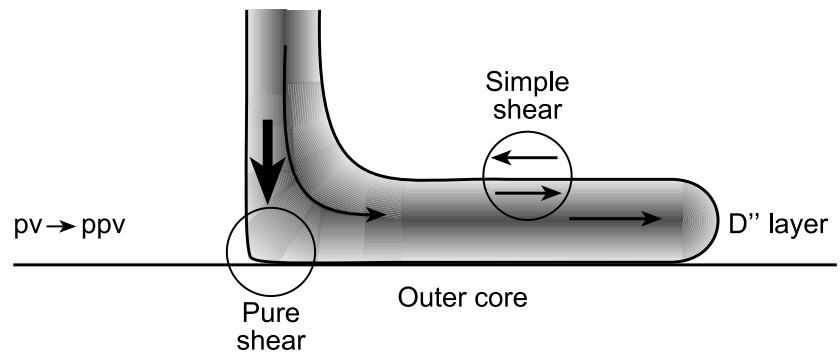

Figure 3. Two examples of external loading (macroscale) of the core-mantle boundary (modified from Karato, 1998a), showing focused sites of shear-induced deformation located at the boundary between the plume structure and surrounding lower mantle material (a) thermal upwelling (simple shear dominant) and (b) loading of CMB by cold, downwelling material (pure and simple shear).

governing the dilatancy effect is the shear modulus $(G)$ of the granular assemblage. Experimental and ab-initio simulations of the ppv phase a function of $P$ and $T$ predict the shear modulus varies from 280 to $300 \mathrm{GPa}$ over a temperature interval of $1000 \mathrm{~K}$ (Stackhouse et al., 2005). The stiffness of the grains another important factor, which itself is a reflection of the porosity (melt fraction). Virtually nothing is known about this quantity under conditions prevailing at the $\mathrm{CMB}$, and we assume a fixed value of $10^{9} \mathrm{~Pa}$ (Petford et al., 2005a). Indeed, given the extreme pressures and temperatures at the coremantle boundary, a purely elastic response to loading is likely to be unrealistic, and viscoelastic effects must be considered for timescales less than about one millenium, or for viscosity in $\mathrm{D}^{\prime \prime}$ exceeding $10^{21} \mathrm{~Pa}$ s. Numerical formulations for twophase flow with a Maxwellian viscoelastic rheology have been developed by Vasilyev et al. (1998) and Connolly and Podladchikov (1998). We have used this 2-D version for investigating melt extraction in multiphase systems at deep mantle conditions where the hydrostatic pressure $P$ is high relative to the bulk modulus $K$. Unlike shallower regions of the earth, $P / K$ is close to unity in the $\mathrm{D}^{\prime \prime}$ layer. The local 


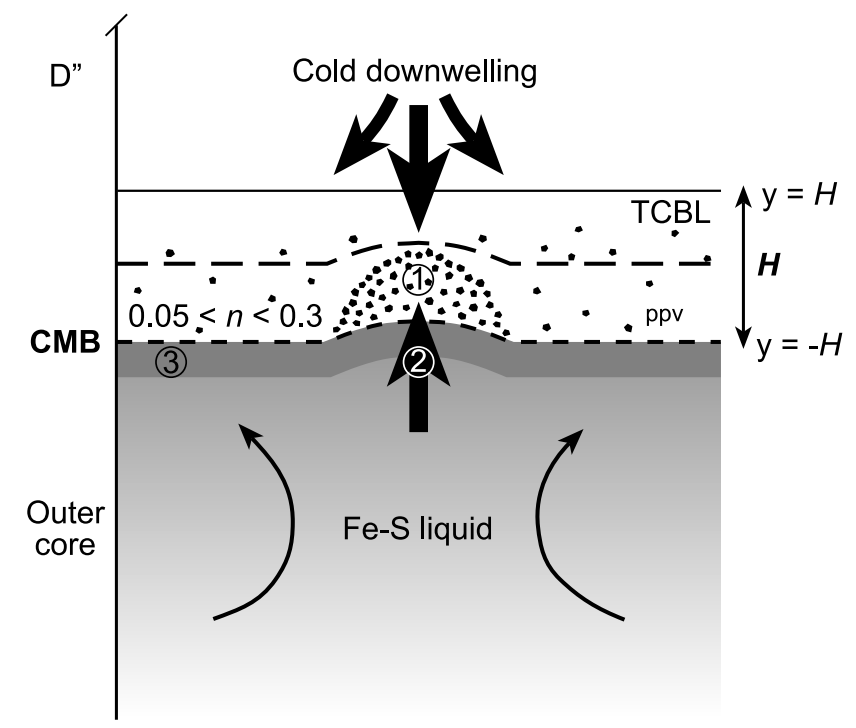

\section{(1) Shear-enhanced dilatancy \\ (2) Upwelling outer core fluid \\ (3) Light element-enriched / sediment layer?}

Figure 4. Diagram showing the simplified geometry of a thermal and chemical boundary layer (TCBL) in the lowermost mantle of thickness $H$ and porosity (n) undergoing loading by downwelling dense material (arrows, see Fig. 4 and Appendix 1 for definitions). Three zones are identified: (1) region of shear-enhanced (poroviscoelastic) dilatancy, (2) upwelling outer core fluid shown as yellow arrow, and (3) Compositionally buoyant upper layer of uncertain thickness and extent that may contain ppv-dominated sediments (Buffett et al., 2000; Alfe et al., 2002). The thermal effect of upwelling core material on the positioning of the pv-ppv phase boundary is approximated by the upper dashed line (from Petford et al., 2005a).

matrix flow regime can be expressed as a function of the Deborah $(D e)$ number, which measures the importance of elasticity in this phenomenon. We expect $D e$ to be of order 1 or greater in the $\mathrm{D}^{\prime \prime}$ layer. The technology of second-generation wavelets (Vasilyev, 2003) can also be brought to bear in the numerical solution of this problem, which is difficult to solve using conventional finite-difference techniques (Connolly and Podladchikov, 1998).

Previous numerical simulations of $\mathrm{D}^{\prime \prime}$ suggest that dense material, concentrated in regions of downwelling, can also be entrained in upwellings. This can result in imposing a topography on $\mathrm{D}^{\prime \prime}$ that is steep and of large amplitude, and whose structure is most likely coupled to the overlying mantle (Loper and Lay, 1995; Olson, 2003). Recently, the dilation model outlined above has been revised to allow explicitly for the effects of Maxwellian viscoelasticity in the granular phase (Koenders and Petford, 2007). This marks an important advance on earlier treatments. Fig. 5 summarizes results from initial scoping calculations aimed at determining the order of magnitude flow and mass flux rates of upwelling outer core liquid across the $\mathrm{CMB}$ in response to deformation-driven dilatancy in $\mathrm{D}^{\prime \prime}$ for the non-viscoelastic case (see Appendix for further details). Fig. 5a uses two end-member values of post-perovskite shear modulus, $3.4 \times 10^{11} \mathrm{~Pa}(\mathrm{~T}=0 \mathrm{~K})$ and $2.85 \times 10^{11} \mathrm{~Pa}(\mathrm{~T}=4000 \mathrm{~K}$; Stackhouse et al., 2005). The results suggest that average flow flow rates $(u)$ into $\mathrm{D}^{\prime \prime}$ are

(a)

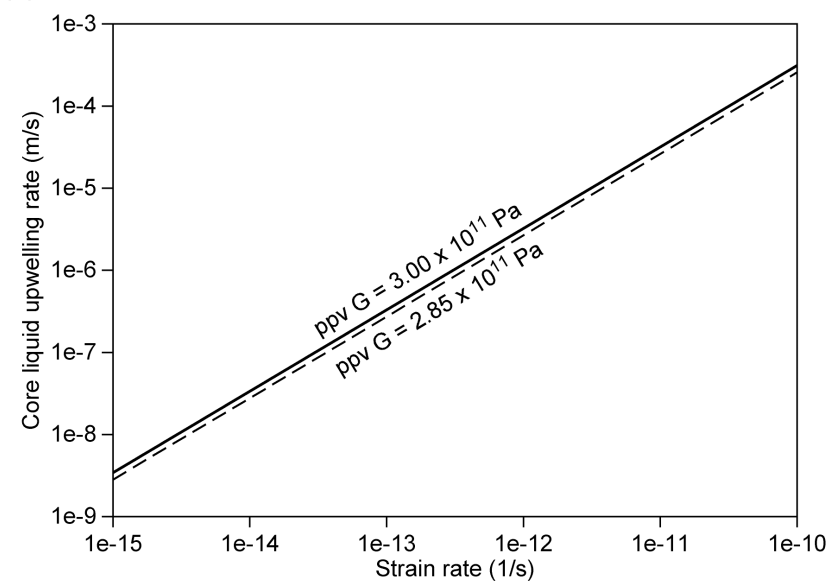

(b)

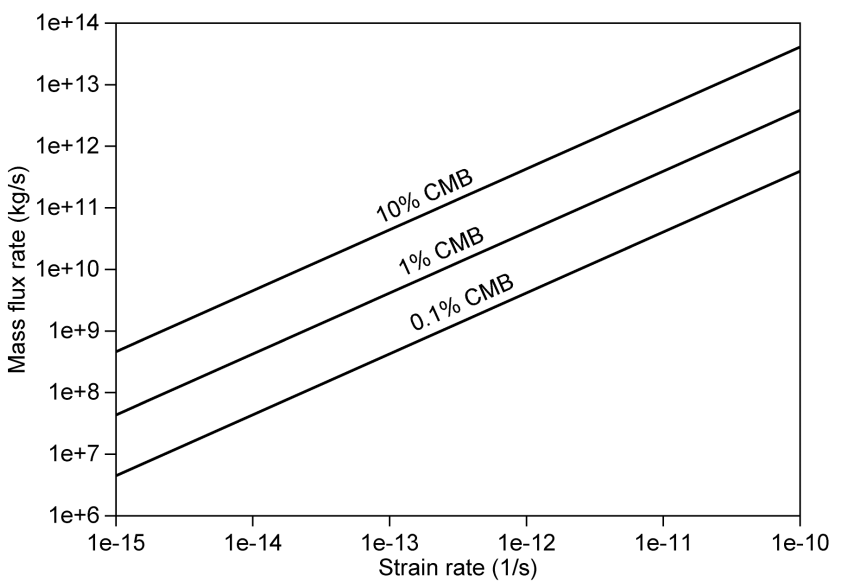

Figure 5. (a) Calculated core liquid metal flow rates $\left(\mathrm{ms}^{-1}\right)$ as a function of strain rate assuming a ppv shear modulus of 340 and 285 $\mathrm{GPa}(0<\mathrm{T}<4000 \mathrm{~K}$; Stackhouse et al., 2005). Upwelling rates due to dilatancy range from c. $5 \times 10^{-9} \mathrm{~m} \mathrm{~s}^{-1}$ to c $10^{-4} \mathrm{~m} \mathrm{~s}^{-1}$ over the calculated strain rate interval. (b) Estimated mass flux rate $\left(\mathrm{kg} \mathrm{s}^{-1}\right)$ of outer core material (assumed density $=10^{4} \mathrm{~kg} \mathrm{~m}^{3}$ ) into D" as a function of loading rate for three cross sectional areas of the core mantle boundary corresponding to $0.1,1$ and $10 \%$ of the total present-day CMB surface area (Petford et al., 2005a). Mass flux increases with increasing rate of strain. 
negligible $\left(<10^{-6} \mathrm{~ms}^{-1}\right)$ until the local strain rate exceeds $10^{-12} \mathrm{~s}^{-1}$. For high strain rates $\left(10^{-10} \mathrm{~s}^{-1}\right)$, flow rates are of the order of $10^{-4} \mathrm{~ms}^{-1}$ (Fig 6a). The potential transport time of infiltrating core fluid given a vertical distance $(H)$ upwards from the $\mathrm{CMB}$ to a height of $10 \mathrm{~km}$ (a length scale characteristic of the observed small scale geophysical heterogeneity in $\mathrm{D}^{\prime \prime}$, Garnero, 2000) is c. $10^{2}$ to $10^{3}$ years, provided loading remains constant at strain rate of $10^{-12} \mathrm{~s}^{-1}$ may result in local rapid changes in electrical conductivity (see also section 3.2 below). If higher rates of strain $\left(10^{-10} \mathrm{~s}^{-1}\right)$ can be achieved, transport times are of the order $10^{8} \mathrm{~s}$ (several years). Estimates of mass flux rates into the base of $\mathrm{D}^{\prime \prime}$ are shown in Fig. $5 \mathrm{~b}$ as a function of area fraction of CMB deformed. The entire $\mathrm{CMB}$ cannot be deformed simultaneously by cold downwellings, and to gain an impression of the effect, three cross sectional areas corresponding to $0.1,1$ and $10 \%$ of the total CMB surface area (c. $1.5 \times 10^{14} \mathrm{~m}^{2}$ ) are used. As with average flow rates, mass flux rates increase with increasing strain rate for a given area of $\mathrm{CMB}$ deformed. For strain rates in excess of $10^{-12} \mathrm{~s}^{-1}$, mass flux rates lie in the range $10^{9}-10^{11} \mathrm{~kg} \mathrm{~s}^{-1}$. At higher loading rates (c. $10^{-10} \mathrm{~s}^{-1}$ ), the mass flux rate across an area of deformation corresponding to $10 \%$ of the CMB may exceed $10^{13} \mathrm{~kg} \mathrm{~s}^{-1}$. Clearly, mass transfer of the type described here will only occur during loading events of appropriate magnitude. However, during a period of protracted

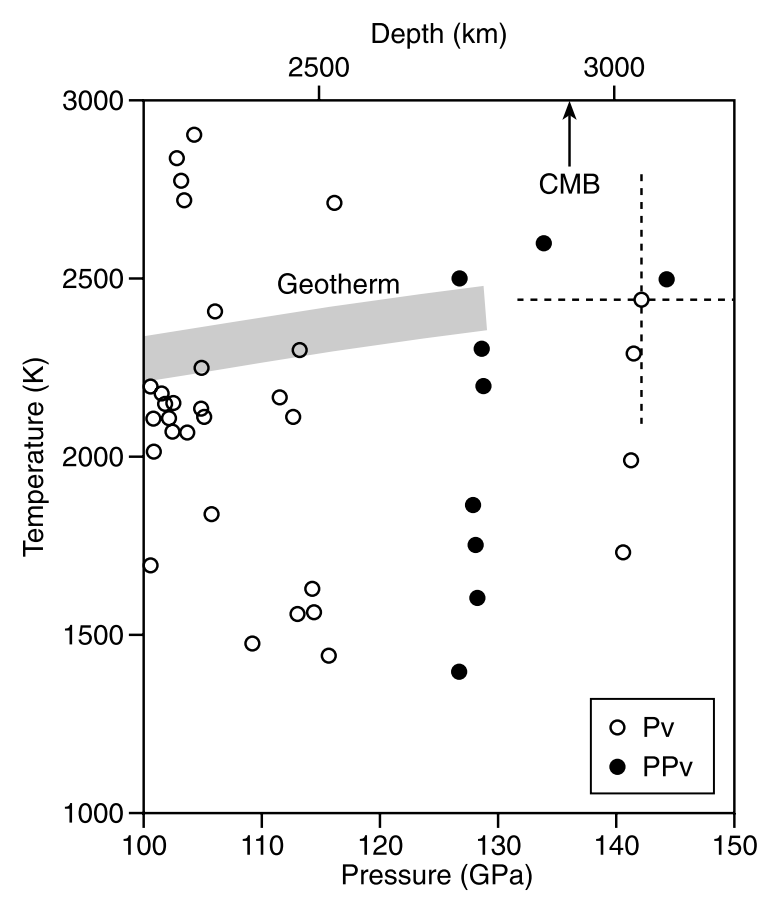

Figure 6. Compliation plot showing perovskite and post-perovskite phase stability at PT conditions relevant to the lowermost mantle and outer core (after shim, 2005). deformation, it may be the case that the amount of dense material transported upwards into $\mathrm{D}^{\prime \prime}$ is sufficient to produce an exchange of angular momentum between solid mantle and the core. Density anomalies in the core-mantle system have been evoked as possible candidate mechanisms for length of day variations (e.g. Kuang, 2003, Holme, 1998). As unlikely as it may sound, a direct consequence of our mass transfer mechanism is a core-mantle coupling with the potential to alter Earth's rotation.

\subsection{Implications of Fe Infiltration on the Composition of Post-Perovskite at the $C M B$}

We emphasize that these results are preliminary and relate to an end-member (ideal) rheology. Nonetheless, they provide some insight into the possible role of deformation-induced instabilities at the CMB in locally drawing up dense, outercore fluid into the lowermost mantle. Moreover, given the strong assumed dependence of the post-perovskite phase transition on composition ( $\mathrm{Fe}$ content), periodic excursions of infiltrating Fe-rich liquid metal from the outer core into the lowermost mantle may profoundly effect the positioning of this transition over time. Also noteworthy is the fact that perovskite can accommodate significant Fe (e.g. over 75 mole\%) under lower mantle conditions and that the incorporation of $\mathrm{FeO}$ might stablize perovskite to higher pressures (Tateno et al., 2007). Either way then the interaction of liquid Fe with silicate perovskite close to the CMB is likely to result in changes in density and seismic properties that will contribute to overall heterogeneity and anisotropy in the lowermost mantle.

Enhanced infiltration of Fe-metallic liquid into D" may also expand the influence played by the chemically induced phase boundary, which could impact at a larger scale those dynamics of $\mathrm{D}^{\prime \prime}$ considered responsible for the generation of superplumes, thus linking the micro and macroscale components. Again at the microscale, the pp-ppv phase change of c. $1 \%$ by volume will result in a stress (pressure) effect that could in principle give rise to differential stresses close to the CMB. Indeed, it is possible that the phase transition itself induces a viscoelastic response capable of driving microscale flow, although more work is needed to confirm the magnitude of the effect. Furthermore, the phase change boundary will vary laterally with temperature. This will result in different depths of $d P / d T$ laterally and may produce strong lateral stress gradients leading to lateral flow, shear-wave splitting and microscale flow.

\subsection{Deformation of Silicate (ppv) Sediments Below the CMB}

While debate continues as to the exact positioning of the perovskite-ppv phase transition within the lowermost mantle, there is evidence to support the idea that the ppv structure may 
be stable at $P T$ conditions appropriate to the outer core (Fig.6). Thus, it seems reasonable to assume that any Fe silicate located there will be dominated by the post-perovskite phase. In a provocative paper, Buffett et al., (2000) showed that viscous compaction in a putative silicate sediment layer will act to expel interstitial core metal liquid and reduce an initial 50\% porosity to a residual value of c. 0.1 on timescales of the order 80-100 Ma. Inspired by this work and the idea that a sedimentary layer may be present at the top of the lower core mantle boundary, we have investigated some consequences that may arise from the local deformation of this layer, in particular the potential for liquid core metal to be drawn upwards into the sedimentary pile. As for the case outlined above for the lowermost mantle, infiltration of Fe-metal into previously compacted sediment below the CMB (Buffett et al., 2000) has a number of potentially significant implications for the shortterm geophysical behaviour of the upper outer core-CMB interface, including rapid changes in electrical conductivity, local composition and heat transport. In this section, we explore the idea that if there is indeed a thin (few km-thick) granular silicate slurry at the top of the outer core, its matrix and transport properties may be more dynamic than first envisioned. A key difference between the Buffett model and the one described here (which are otherwise complementary), relates to the rheology and microscale deformation behaviour of the assumed ppv-dominated sediment. As with our model for mantle deformation above, we assume the bulk material will dilate in response to an applied shearing stress. The effect causes the medium to expand, implying that pore space becomes available for the pore fluid, again noting that there are no voids in the system (in this case the pore fluid is trapped Feliquid metal). The model requires fixing material properties for the permeability and stiffness of the solid phase. Thus, the material properties of the sediment have to be considered. Buffett et al., (2000) assumed an arbitrary grain size of $10^{-7} \mathrm{~m}$, similar to that of fine clay, but acknowledged that there is no direct evidence for this parameter range. As dilatancy has not been observed in materials where the grain size is $<1$ micron, specimen calculations are performed assuming flocculation into clumps larger than the mean particle size. We find that grain clump sizes $\geq 10^{-4} \mathrm{~m}$ (100 microns) in the sediment layer, the dilation effect can result in significant fluid flow.

As with silicate mantle, we assume the putative sediment pile undergoes loading due to deformation effects that are external to the layer. Loading may be caused by fluctuations in convection velocity in the fluid outer core that cause stresses to propagate normal to the layer, or deformation from above the CMB in the lower mantle $\left(\mathrm{D}^{\prime \prime}\right)$, again due to downwelling of cold material (e.g. Karato, 1998a,b; Petford et al., 2005b). On shorter timescales, there is little doubt that the outer core is convecting turbulently (Olson, 2003), giving rise to shearing strains concentrated at the sediment-liquid interface. "Geomagnetic jerks", caused by sudden accelerations in outer core liquid (Bloxham et al., 2002) also provide an attractive, if poorly understood, candidate mechanism.

Order of magnitude estimates of the local flow rate of liquid metal upwards into the dilating sediment layer $1 \mathrm{~km}$ thick are very small $\left(<10^{-9} \mathrm{~ms}^{-1}\right)$ where the loading rate is comparable to mantle convection rates $\left(10^{-15} \mathrm{~s}^{-1}\right)$. However, at rates of strain in excess of $10^{-12} \mathrm{~s}^{-1}$, flow rates increase markedly (in tandem with threshold changes in excess pore fluid pressure), and at high loading rates (c. $10^{-10} \mathrm{~s}^{-1}$ ), upwelling velocities approach values characteristic of outer core convection velocities $\left(0.1 \mathrm{~mm} \mathrm{~s}^{-1}\right.$, Whaler, 1986). Total transport time of core liquid upwards through the layer is of the order $10^{7}-10^{10} s$ (c. 1 to 300 years) depending on the loading rate. Thus, provided the sediment pile can be deformed externally at rates $\geq 10^{-12} s^{-1}$, upwards infiltration of liquid core metal into the compacted upper sediment layer is expected to occur over for the duration of the loading event.

Several interesting geophysical implications follow on that are relevant to the core mantle boundary region. Most notable are changes in electrical conductivity when compared to estimates of this parameter based on the Buffett et al (2000) compaction model. The presence of an eclectically conducting layer along the core mantle boundary is well known (e.g. Garnero, 2000), but its precise location (mantle side or outer core) remains unclear. In the Buffett et al., (2000) model, compaction in the upper part of the sediment layer resulted in expulsion of more dense core liquid, and a corresponding upwards reduction in electrical conductivity, from an initial value of $1.75 \times 10^{5} \mathrm{Sm}^{-1}$ to c. $10^{5} \mathrm{Sm}^{-1}$ where the conductance of the order $10^{8} \mathrm{~S}$. The relationship between electrical conductivity $(\sigma)$ and sediment transport properties is given by Archie's law: $\sigma=n^{\chi} \sigma_{c}$, where $n$ is porosity, $\chi$ is a constant (1.5) and $\sigma_{c}$ is the electrical conductivity of liquid iron $\left(5 \times 10^{5} \mathrm{Sm}^{-1}\right)$. A consequence of the dilatancy effect is that upwelling of core liquid metal into the compacted region will locally raise the electrical conductivity there, leading to fluctuations in electrical properties in regions undergoing active deformation. As an illustration of this, Fig. 7 shows how $\sigma$ will change in an initially well compacted region of sediment $(n=0.05)$ away from its background value $\left(5.5 \times 10^{3} \mathrm{Sm}^{-1}\right)$ as the porosity increases on dilation. Depending upon the exact choice of Fe liquid conductivity, the electrical conductivity could in principle increase thirty fold relative to the initial background value in highly dilatant, large porosity $(n>0.3)$ regions.

Another important consequence of the dilatant effect relates to heat flux. Sediments should accumulate in valleys where heat flux across the CBM is lower than average (Olson, 2003). However, disruption and infiltration of the sediment pile by hotter upwelling liquid might act to pump heat locally into the lower mantle. Hofmeister (2005) has suggested that the thermal conductivity of lower-mantle minerals should decrease 


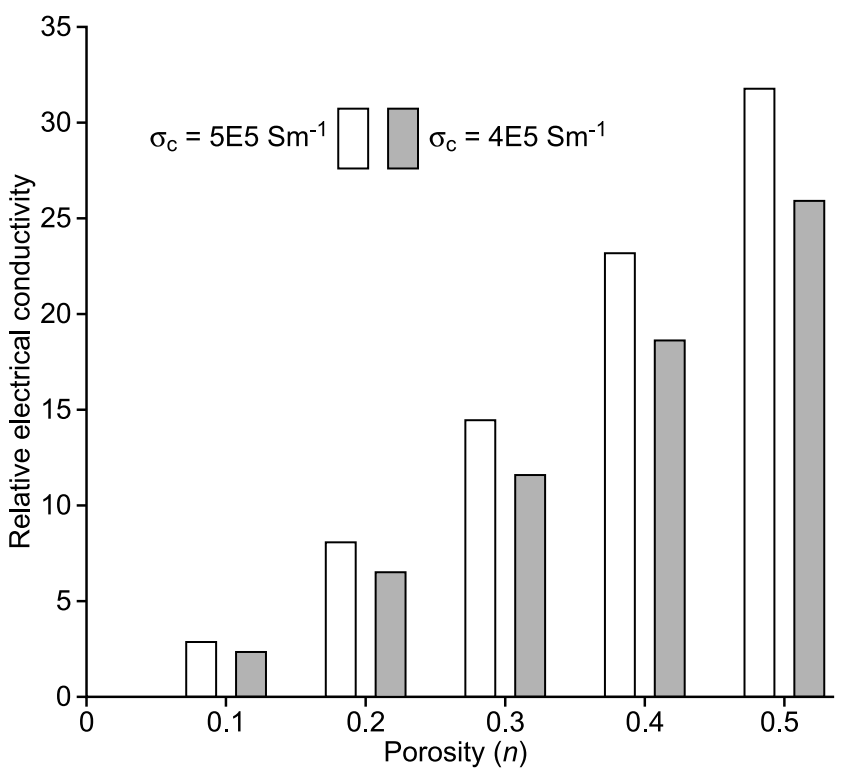

Figrue 7. Plot showing relative electrical conductivity in the sediment layer $1 \mathrm{~km}$ beneath the CMB normalised to a background conductivity $\left(5.5 \times 10^{3} \mathrm{Sm}^{-1}\right)$ at $5 \%$ porosity (after Buffett et al., 2000). Increasing the local porosity in the layer due to dilatancy also increases the electrical conductivity of the layer. Results are given for two values of liquid Fe metal conductivity $\sigma_{\mathrm{c}}=5 \times 10^{5} \mathrm{Sm}^{-1}$ (light grey) and $\sigma_{\mathrm{c}}=4 \times 10^{5} \mathrm{Sm}^{-1}$ (dark grey).

with increasing Fe content. With respect to the scale hierarchy of processes outlined earlier, this could give rise to an interesting non-local effect in which $\mathrm{Fe}$ drawn into the source region of a mantle plume developing at the $\mathrm{CMB}$ would selectively heat up the interior. This would lower the plume viscosity, leading to a scenario involving a hot accelerating jet, fueled by the infiltrated iron. Fresh liquid iron drawn up into contact with the silicate part of the lowermost mantle also provides an opportunity to refresh the basin with new sediment, a process unlikely to occur during compaction as Fe liquid metal is driven out of the pile away from contact with the overlying mantle. Finally, as already outlined, the Fe mole fraction in the post-perovskite phase lies in the range 0.2 to 0.8 (Mao et al., 2004). The potential for partitioning large amounts of iron into the ppv structure means that ppv-dominated sediment could be up to $20 \%$ more dense that Fe perovskite (see also section 3.2) Gravitational compaction of a high density ppv slurry would thus be slower than that of Fe perovskite due to the reduced density contrast between grains and ambient fluid.

\subsection{Microscale Physical Processes: Experimental Deformation Studies}

Experimental studies on metallic liquid and silicate systems provide a direct approach to core-mantle interaction driven by deformation processes. While conducting ultra-high pressure deformation experiments on dilatancy are challenging (e.g. Petford et al., 2006), insight into metal liquid and silicate interaction under stress can be gleaned from lower pressure deformation experiments that provide some insight into the range of physical migration processes and the associated geochemical response. Changes in melt migration processes and geochemical signatures conducted on a natural $\mathrm{H} 6$ chondrite, composed of $25 \% \mathrm{FeNi}$ and $\mathrm{FeS}$ and silicate phases olivine and pyroxene at 1.0-1.3 GPa, under pure shear are presented in Rushmer et al. (2000) and Rushmer et al. (2005). In summary, the experimental charges show micro-veining and modification of the silicate phase compositions by migrating Fe-Ni-S-O metallic liquid (the eutectic composition at the onset of metallic melting). Deformed charges also reveal textures consistent with $\mathrm{Fe}-\mathrm{Ni}-\mathrm{S}$ liquid quench occupying dilatant zones formed subparallel to the maximum compression direction, as shown in Fig. 8 (see also Plate 1c in Rushmer et al., 2005). We regard this as a critical observation. In all experiments where silicate melt is absent or present only in low volumes, metallic liquid is observed in dilatant shear zones, along grain boundaries or in zones of hydrofracture that develop at higher strain rates. These textures provide supporting evidence for the microscale segregation processes and Fe-infiltration model and suggest

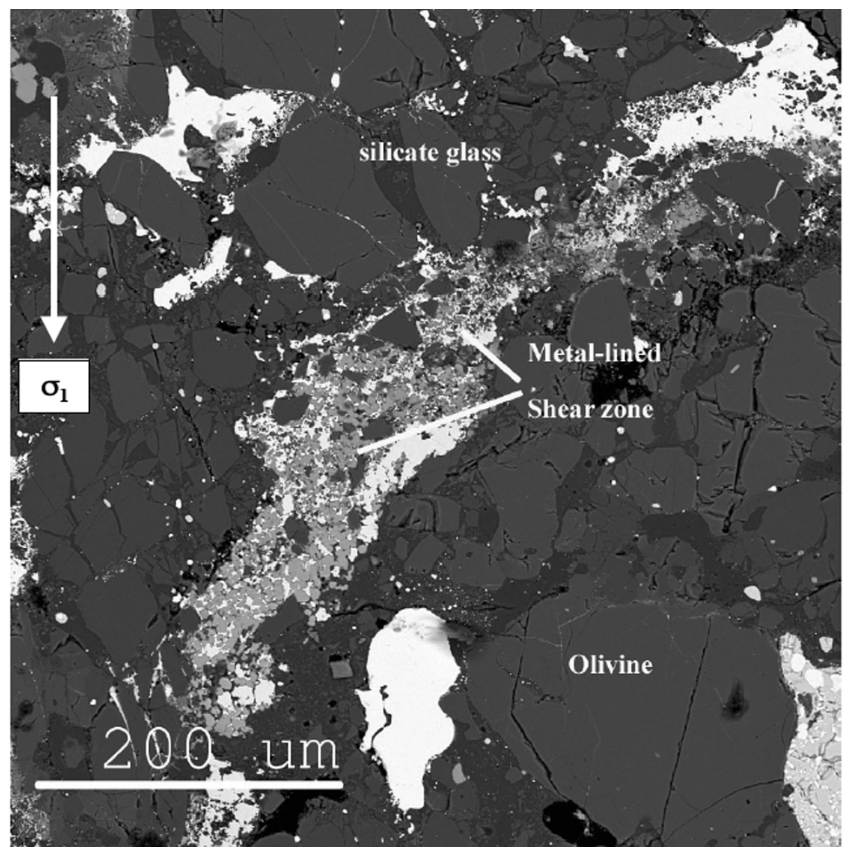

Figure 8. Deformed Kernouve H6 Chondrite sample (KM-18). The experiment was performed at a strain rate $10^{-4} \mathrm{~s}^{-1}$, a pressure of 1.3 $\mathrm{GPa}$ and temperature of $950^{\circ} \mathrm{C}$. Applied stress $\left(\sigma_{1}\right)$ at constant strain rate is from the top of the image down, vertically. Shearing develops at an angle to the applied stress and is filled with metallic liquid (now quench). 


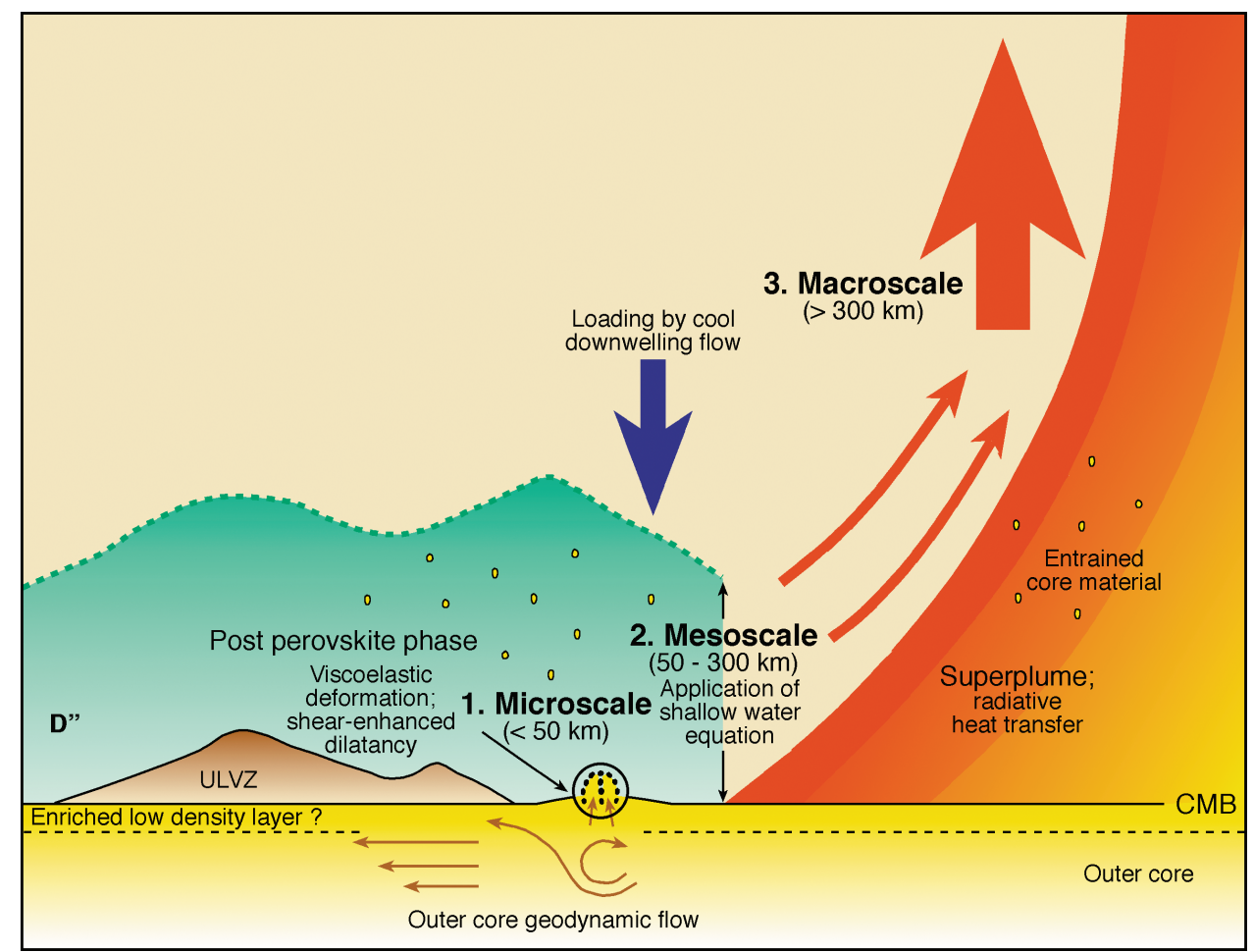

Plate 1. Summary diagram showing the proposed relationship between each of the three key length scales described in the text, along with their characteristic lengthscales: (1) Microscale $(<50 \mathrm{~km})$ shear induced matrix deformation and core liquid entrainment in $\mathrm{D}^{\prime \prime}$, (2) Mesoscale $(50-300 \mathrm{~km})$ internal boundary layer flow and density-driven sub-layer convection modeled using the shallow water equations, (3) Macroscale (>300 km) superplume initiation coupled with radiative heat transfer close to the CMB. 
that external loading can result in dilatant behaviour in relevant materials during the initial stages of deformation.

Preliminary results from high-pressure simple shear experiments investigating dilatancy in silicate-FeS systems performed at confining pressures of $3 \mathrm{GPa}$ (used to inhibit brittle behaviour of the silicate matrix) are reported by Petford et al (2006). Despite the known high dihedral angle between FeS melt and silicate (Shannon and Agee, 1996), the experiments revealed that FeS liquid was highly mobile during deformation. Liquid FeS routinely segregated towards the top of the deforming sample layers, and textural evidence ofearly dilatantion was clearly preserved in some experimental runs. Detailed analysis of the resultant solid-melt microstructures is currently underway. But the observation that migration of FeS melt upwards in the experimental charge (i.e. against gravity) suggests that transient granular dilatancy and associated pressure gradients driven by shear, as predicted in theoretical models of Petford and Koenders (2003), lends further support to the basic physics underlying the microscopic regime (Fig. 9). However, we acknowledge it is a big step to extrapolate these textural observations to processes operating at the core-mantle boundary, and further experimental confirmation relating to the specific mechanism of shear-enhanced dilatancy at high pressure is needed (Petford et al., 2006), along with more data on the deformational behaviour of post-perovskite and relevant analogs (e.g. Yamazaki et al., 2006).

Deformation experiments are not only important for testing our ideas underpinning the microscale regime, but also in helping improve our overall understanding of the rheology of the lowermost mantle and core-mantle boundary region. Experimental deformation studies can also be combined with observations made via geoid anomaly data (e.g. Cadek and Fleitout, 2006) to provide additional insight into the rheology of the lowermost mantle. Inversion of lateral viscosity distributions in the lower mantle obtained using long-wavelength geoid anomaly data (Cadek and Fleitout, 2006) reveal an interesting pattern of high viscosity regions associated with slow seismic velocity anomalies, and low viscosity regions found in regions with fast velocities. From a macroscale perspective, this scenario can be explained by a model whereby downwelling slabs are transformed at their leading edge to post-perovskite and become less viscous. Their lower viscosity allows them to spread laterally so that together they pin down stiff, hot upwelling plumes. This situation is shown in Fig. 10, where the sinking slabs act to stabilize the hot, but rheologically strong, pervoskite plumes in the deep mantle.

\subsection{Microscale Physical Processes and Associated Geochemistry: Fe-Ni-S Liquid Entrainment and Possible Fe-Enrichment of Silicates}

The extent to which Fe-enrichment due to core-mantle interaction in the $\mathrm{D}^{\prime \prime}$ region is a real processes or a geochemical artifact is proving controversial (Walker and Walker, 2005). As already mentioned, the greater density of liquid iron alloy and its immiscibility with silicate rock creates a highly efficient physical barrier between mantle and core. However, there are no significant reasons why the Earth's mantle should be chemically isolated from the core. Indeed, Brandon and Walker (2005) claim that the D" region is one of the most chemically reactive regions of Earth's interior. Several mechanisms have been proposed to account for the required coremantle interaction. One is the microscale processes described above where core liquid is physically incorporated directly into $\mathrm{D}^{\prime \prime}$ by shear and subsequently tapped by CMB-derived plumes. This model could give rise to the isotopic systematics observed in Os and W (e.g. Walker et al., 1995; Brandon et al., 2003; Brandon and Walker, 2005). A complementary process, operating in tandem with physical entrainment, arises out of chemical reactions between migrating liquid $\mathrm{Fe}$ $\mathrm{Ni}-\mathrm{S}(\mathrm{O})$ and the surrounding silicate matrix. It is proposed that such chemical exchange could locally produce Feenriched silicates (e.g. Humayun et al., 2004) which are in turn tapped by CMB-derived plumes, enriching them with high $\mathrm{Fe} / \mathrm{Mn}$ ratios but without any corresponding metallic component that would generate clearly distinguishable isotopic heterogeneities. In this way, Fe/Mn is decoupled from ${ }^{186} \mathrm{Os}-{ }^{187}$ Os ratios during physical entrainment at source. In addition, as the outer core crystallizes, $\mathrm{W}$ and Os can be decoupled due to differences in partitioning behaviour (W has a lower $K d$ for the metallic residual metal than Os, Humayun et al., 2004). Thus, depending upon the plume source process history, $\mathrm{W}$ and $\mathrm{Os}$ isotopic ratios and $\mathrm{Fe} / \mathrm{Mn}$ ratios need not correlate in plume-derived materials sampled at the Earth's surface, and the presence/absence of one or the other are not in themselves unique indicators (the 'smoking gun') either in support or as evidence against of core-mantle interaction. Less controversially, continued differentiation of the liquid outer core to form the solid inner core over time is likely to have increased the overall abundances of the light element constituents ( $\mathrm{FeS}, \mathrm{FeO}$, etc.) to the point of exsolution at the CMB (Brandon and Walker, 2005). Existing $\mathrm{Fe} / \mathrm{Mn}$ data from Gorgona and Hawaiian samples help place some limits on the possible types of chemical reactions that may occur at the CMB. One such reaction between an outer core composed of $\mathrm{FeO}-\mathrm{FeS}-\mathrm{Fe}(\mathrm{O}$ and $\mathrm{S}$ being the light elements that ensure the outer core is liquid by reducing the solidus of $\mathrm{FeNi}$ ), and silicate mantle $(\mathrm{Mg}, \mathrm{Fe}) \mathrm{O}$ comprising perovskite and magnesiowustite is:

$$
(\mathrm{Mg}, \mathrm{Fe}) \mathrm{O}+\mathrm{FeO}+\mathrm{FeS}+\mathrm{Fe}=\left(\mathrm{Mg}, \mathrm{Fe}^{*}\right) \mathrm{O}+\mathrm{Fe}-\mathrm{FeS}
$$

In this reaction, the outer core would contribute $\mathrm{FeO}$ in the silicate form to any subsequent mantle plume, leaving Fe-FeS as residual metallic liquid in $\mathrm{D}^{\prime \prime}$. Os isotopes see this metal, but more randomly than the interaction via $\mathrm{FeO}$ with the 


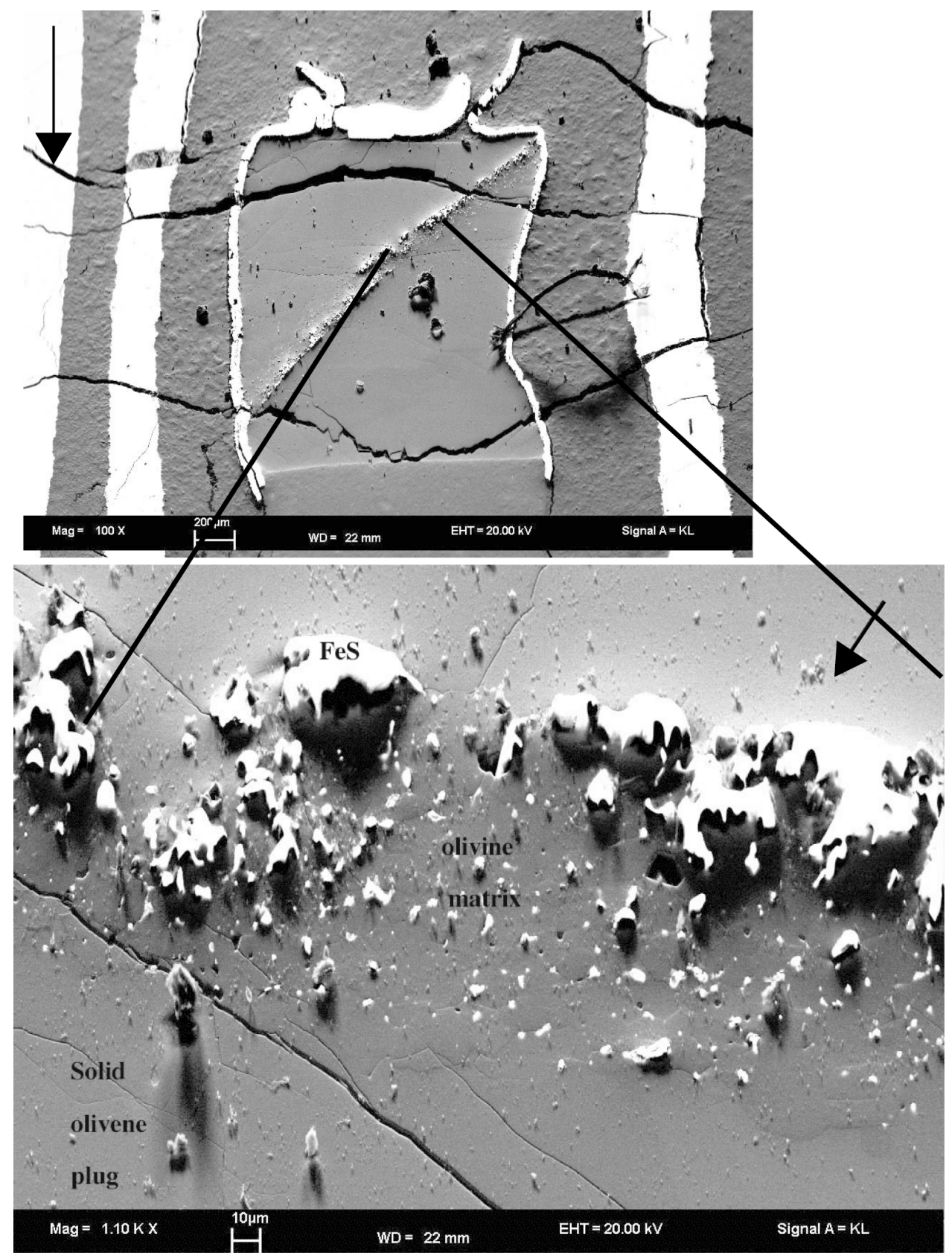

Figure 9. Simple shear experiment performed on FeS and Olivine matrix with solid olivine at $3 \mathrm{GPa}$ and $1200^{\circ} \mathrm{C}$. Before melting and simple shear, FeS was distributed evenly across the olivine matrix. After shear, a small fault was seen to cut the sample midway. During deformation, molten FeS has migrated to the top of the layer (right hand side of top image) and to the bottom (left hand side, top image). The lower image is a close-up of the sample, showing that liquid FeS has migrated upwards to collect at the top of the deformed layer.

silicates. Therefore, mantle plumes derived from a transiently sheared core-mantle boundary may be higher in $\mathrm{FeO}$ (Fe/Mn ratios), but, Re-Os systematics may be decoupled.

Rushmer et al. (2005) noted the enrichment of silicate phases through interaction with liquid metal during shearing deformation. In contrast, experimental studies at high pressures but without deformation (e.g. Knittle and Jeanloz, 1991 Takafuji et al. 2005; Sakai et al. 2006; Asahara et al. 2007) suggest that $O$ will be incorporated preferentially into the liquid Fe. Such observations may help explain the apparently conflicting chemical signatures in some magmas believed to have been sourced from plumes originating deep 


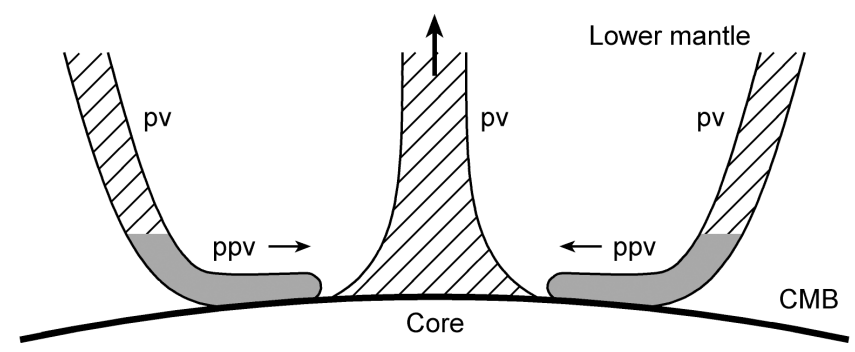

Figure 10. Cartoon showing role of large-scale (macroscale) deformation and interaction at the $\mathrm{CMB}$ as inferred from long-wavelength geoid anomaly data (Cadek and Fleitout, 2006) in relation to the pvppv transition. Fast sinking slabs, transformed to post-perovskite, have lower viscosity and can spread laterally. This could act to destabilize hot, but strong, pervoskite plumes in the deep mantle.

in the mantle. It also seems likely that variations in $\mathrm{fO}_{2}$ are important. This is confirmed by Asahara et al., (2007) who found that at high pressures in the system magnesiowustite plus liquid iron, $\mathrm{FeO}$ partitions into magnesiowustite. One consequence, given chemical equilibrium between mantle and core, is the presence of a thin layer at the base of the mantle, highly depleted in $\mathrm{FeO}$.

\section{MESOSCALE PROCESSES: PETROLOGICAL AND THERMAL-MECHANICAL INTERACTION BETWEEN THE PPV BOUNDARY AND OUTER FLUID CORE}

We now address the effects of mescscale processes and ther relationship with the 'leaky' core hypothesis. Gerya et al., (2006) have developed a 2-D numerical model of coupled petrological-thermomechanical and porous flow processes at the CMB. Along with core-mantle interaction (microscale processes), chemical-mechanical changes in $\mathrm{D}^{\prime \prime}$ may also result from contamination by floundering, Fe-rich, oxidized slab fragments reaching the CMB (Fig. 2) and changes in lower mantle convection style resulting from small scale convection within a denser Fe-rich D"-ppv layer. Recently a selfconsistent, mesoscale petrological-thermomechanical model of the lowermost mantle has been derived (Connolly, et al., 2005; Gerya et al., 2006, Gorczyk et al., 2007) that explicitly accounts for density changes due to phase transitions involving $\mathrm{ppv}$ in both the continuity and the momentum equations, along with relevant latent heat reactions and energy conservation equations that include shear heating. The time-dependent continuity equations, solved in Lagrangian form with substantive time derivative of density computed from moving active markers, use a viscoelastoplastic rheology (Gerya et al., 2006, Connolly et al., 2005). The mesoscale model includes the various nonlinear dependences of thermal conductivity, which has a strong radiative component (see also section 3.5 below). Initial results suggest that undulations in the thickness of $\mathrm{D}^{\prime \prime}$ can result from the interplay of temperature and composition on the pv-ppv phase transition. Thermally-driven undulations of the pv-ppv phase boundary can be significant due to the large Clapeyron slope. Temperature excursions of $100 \mathrm{~K}$ and $500 \mathrm{~K}$ give rise to $17 \mathrm{~km}$ and $85 \mathrm{~km}$ deflections of the boundary, respectively. Traditionally, undulations of the phase boundary have been attributed strictly to thermal perturbations associated with erupting plumes (Schubert et al., 1975). However, there is increasing evidence that deep mantle plumes respond to local chemical potential (Yuen et al., 1993; Ishii and Tromp, 1999; Trampert et al., 2004). Therefore, the possibility that the pv-ppv phase boundary undulation is in part compositional, reflecting variations in $\mathrm{Fe} / \mathrm{Mg}$ within a chemically heterogeneous $\mathrm{D}^{\prime \prime}$, requires serious consideration. It may also follow that the transition pressure (depth) may vary with the molar fraction of Fe replacing $\mathrm{Mg}$ in the ppv lattice. The approximate relative magnitudes of thermal and chemical perturbations still need to be investigated. However, one implication of $\mathrm{Fe}$ infiltration due to shearing is that the $\mathrm{Fe} / \mathrm{Mg}$ ratio in post perovskite, hence the location of the phase transition (section 3.1), close to the CMB may be position-dependent and linked with tectonic events (downwelling of slabs, upwelling of outer core fluid).

\section{MACROSCALE PROCESSES: THERMAL- CHEMICAL (SUPER)PLUMES WITH RADIATIVE THERMAL CONDUCTIVITY}

The presence of a thermal boundary layer at the core-mantle interface requires conductive heat transfer to take place across the CMB. Heat transport by thermal conductivity involves two different mechanisms: scattering involving lattice vibrations $\left(k_{\text {lat }}\right)$ or diffusive emission-absorption exchange of photons $\left(k_{\mathrm{rad}}\right)$. Previous results show $\partial k_{\mathrm{lat}} / \partial T$ is negative whereas $\partial k_{\mathrm{rad}} / \partial T$ is positive (e.g., Hofmeister, 2004), leading Dubuffet et al. (2002) to conclude that vibrational transport invigorates convection through feedback in the temperature equation (boundary layers are destabilized and convection is made more chaotic and time-dependent), whereas radiative transport weakens convection by stabilizing the flow. Recent work (e.g. Hofmeister, 2005, 2006), has shown that the temperature dependencies are more complicated than previously thought, with strong ramifications for large scale (superplume) initiation in the lower mantle. Radiative, diffusive transfer inside the Earth is governed by two factors: the mean free path traveled by photons, and the photon flux. In turn, both factors depend on grain size (Fujisawa et al., 1968; Brewster, 1992; Hapke, 1993; Kaufmann and Freedman, 2002). However, only recently has grain size been included in calculating $k_{\text {rad }}$ (Hofmeister, 2006). In Earth's lower mantle, energy absorptions in the 
visible range are dominated by electronic transitions in $\mathrm{Fe}^{2+}$ with $k_{\text {rad }}$ a direct function of the concentration of $\left[\mathrm{Fe}^{2+}\right]$. The threshold effects and flattening of $k_{\text {lat }}$, which also exhibits threshold behavior, have ramifications on the style of mantle convection as shown by the results of Dubuffet et al. (2002). The specific domains in thermal conductivity suggest sluggish lower mantle flow, but a strongly time-dependent pattern above $670 \mathrm{~km}$. That radiative transfer decreases as $\mathrm{Fe} /(\mathrm{Fe}+\mathrm{Mg})$ increases beyond 0.1 suggest that thermo-chemical plumes can form at the base of the lower mantle through a positive feedback involving chemical enrichment (e.g. shear-induced dilatancy on the microscale), thermal conductivity, and temperature-dependent viscosity. This combined set of processes would be most effective at stagnant points of the upwelling.

\subsection{Global Implications}

Models of thermal convection and mantle dynamics are now being constrained by the post-perovskite phase transition. This advance, combined with the microscale and mesoscale processes outlined above that argue for a chemically diverse $\mathrm{D}^{\prime \prime}$, have the potential to deepen significantly our understanding of mantle gedynamics on a global scale, and in particular the formation of superplumes. Recent geodynamical simulations (Matyska and Yuen, 2005, 2006; Nakagawa and Tackley, 2004, 2006) have focused on the ppv phase transition itself. However, these studies differ in that the model of Matyska and Yuen $(2005,2006)$ makes explicit use of the radiative component of thermal conductivity in the fluid dynamic calculations (see section 5 above). For all other parameters fixed (e.g. Rayleigh number, spinel to perovskite upper-mantle phase transition, depth-dependent viscosity etc) superplumes only develop where radiative thermal conductivity is included explicitly in the calculations (Fig. 11). We regard this result, linking the microscale and macroscale aspects of our model through 3-D numerical solutions and thermal-chemical convection in $\mathrm{D}^{\prime \prime}$ with the post-perovskite phase transition, as a significant development. Although still incomplete, as the transition pressure of the phase change depends on both thermal and chemical variations associated with lower-mantle dynamics (section 4), we believe we have moved forward in our understanding of thermal-chemical convection with a phase transition.

Additional factors that follow on from a better understanding of the thermal and chemical variations that influence lower mantle dynamics are the role of Fe-enrichment and plume flux rates (Nolet et al., 2006). Observations indicate clear variations in flux strength (Hawaii high, Azores, low) of deep sourced mantle plumes (Montelli et al., 2004). If temperature alone is the driving force for upwelling, it is not clear why this should result in such variable flux rates. Could $\mathrm{k}=1$ :

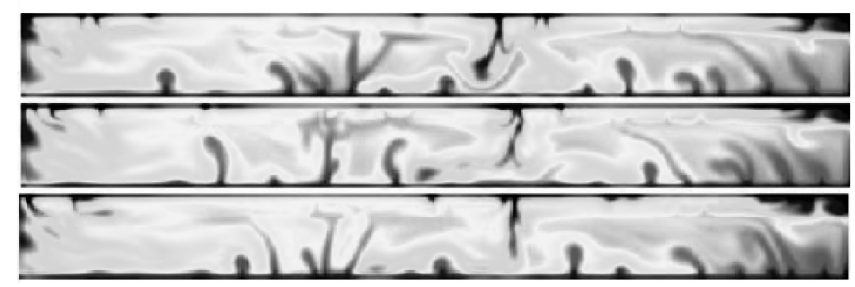

$\mathrm{k}=\mathrm{k}(\mathrm{T})$

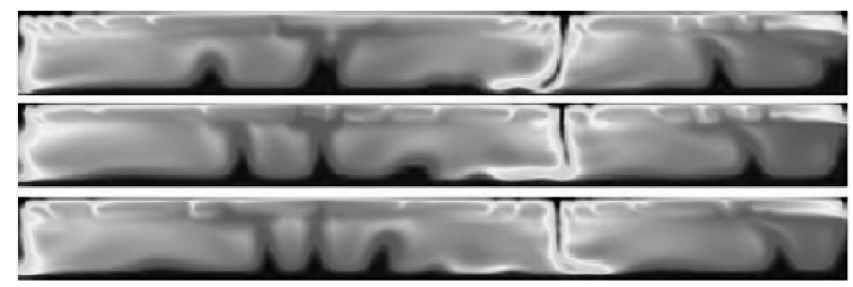

Figure 11. Figure from a numerical simulation into the effects of radiative heat transfer on plume nucleation at the CMB. The two models show contrasting temperature fields that highlight the strong effect of a small amount of radiative thermal conductivity $(k=k(T))$ resulting in an overall conductivity increase of around 50\% (from Matyska and Yuen, 2005).

compositional variations play a role too? Clearly we still have much to learn. However, it is apparent that the next generation of geodynamic models must incorporate a chemically diverse $\mathrm{D}^{\prime \prime}$ layer appropriately parameterized to include the mineralogical and seismic properties of post-perovskite and its position-dependent phase transition.

\section{SUMMARY}

We have presented a model that views lower mantle convection as a series of linked, hierarchical processes. The emerging picture is one of a highly dynamic region modified by significant interaction and exchange, both chemically and physically between post-perovskite dominated silicate and outer core fluid. The "leaky core" hypothesis requires an appropriate transport mechanism and we propose a model to account for this that involves regional deformation of ppv silicate triggering a local dilatant effect that sucks up core fluid. We define this aspect of the problem as contributing to the microscale $(<50$ $\mathrm{km})$ dynamics of $\mathrm{D}^{\prime \prime}$. Some important meso $(50-300 \mathrm{~km})$ and macroscale $(>300 \mathrm{~km})$ geodymanical implications follow on from our micorscale model. Firstly, it provides a mechanism for imparting a distinctive HSE chemical signature into the lowermost mantle, that links known large scale mantle flow processes with recent geochemical observations for core-mantle interactions. Secondly, given the strong dependence of the perovskite and post-perovskite phase transition on composition, periodic 
excursions of infiltrating Fe-rich metal from the outer core into the lowermost mantle may have profoundly effected the positioning of this transition over time, and contributed also to sublayer mesoscale convection driven in part by density gradients. Even if upwelling core metal does not instill a strong chemical potential in D", it is likely to produce a rheological effect that could influence the elastic properties of ppv and produce changes in electrical conductivity. Fe-rich ppv may be responsible for ultra low velocity zones, although other mechanisms related to topography such as sedimentation in CMB basins, which may themselves be deformed to produce local changes in electrical conductivity, should not be ruled out. Encouragingly there is some experimental evidence in support of the dilatant mechanism at elevated PT conditions. Finally, Fe-rich ppv in the lowermost mantle resulting from leaky core infiltration will influence the nature of thermal conduction across the CBM.

Acknowledgments. We thank Renata M. Wentzcovitch, Curt Koenders and the ITR and CSEDI NSF programmes. NP thanks Nico Walte, Bayerisches Geoinstitut and funding from the EU Research Infrastructures Transnational Access Programme. TR thanks NASA (grant NAGS-10463) for supporting the deformation study of the Kernouve meteorite. Two anonymous reviewers and K. Hirose are thanked for helpful comments.

\section{APPENDIX}

The dilatancy effect is a key component of the microscale process. The model put forward is described in detail in Petford and Koenders (2003) but summarised here for completeness. The total stress is $\sigma_{i j}=\sigma_{\mathrm{ij}}^{\prime}-p \delta_{i j}$ where $p$ is the excess pore pressure and $\sigma^{\prime}$ is the skeletal stress (Terzaghi, 1943). The vertical coordinate is $y$, the two horizontal coordinates are $x$ and $z$. The stress equilibrium requires that $\partial \sigma_{i j} / \partial x_{j}=0$ which for a problem that does not depend on $x$ and $z$ results in $\sigma_{x y}^{\prime}=c(t)$ and $\sigma_{y y}^{\prime}=p-d(t)$, where $c(t)$ and $d(t)$ are time dependent constants. Biot's equation for the consolidation of an incompressible fluid flowing through a porous material with position-dependent permeability $k(\mathrm{x})$ takes the special form:

$$
\frac{\partial}{\partial y}\left(k(y) \frac{\partial p}{\partial y}\right)=n \beta \frac{\partial \dot{v}}{\partial y}+\frac{\partial p}{\partial t}
$$

where $v$ is the displacement of the granular material, $n$ is the porosity (melt fraction), and $\beta$ is the fluid (Fe-metal) compressibility. Time differentiation is denoted by a dot. Although Biot's theory describes well the mechanical behaviour of porous media under compaction, it does not take into account the coupling between volume strain and shear stress that in granular materials results in dilatancy. Koenders and Petford (2000) and Petford and Koenders (2003) give a modified form of Eq. (1) that takes into account the effects of coupled shear strain and volume stress. The reader is referred to Petford and Koenders (2003) and Koenders and Petford $(2005,2007)$ for a full treatment of the mathematical details of granular aggregates deforming under pure and simple shear that includes also the effects of rate-dependency. The basic model is incremental, and by assigning fixed material properties for the permeability and stiffness of the solid phase, Eq. (1) can be rewritten as:

$$
k_{0} \frac{\partial^{2} p}{d y^{2}}=\frac{1}{a_{1}}(\dot{p}-R \dot{c}(t))
$$

where $\dot{p}$ is the excess pore pressure, $\dot{c}$ is the shear stress rate, $R$ is a non dimensional constant of 1 and $a$ is a measure of the granular stiffness of the sediments comprising the layer. Under appropriate boundary conditions $p(H)=0$ (there is no excess pore fluid pressure at the bottom of layer of thickness $H$ ), and $\partial p / \partial y=0$ (the layer is virtually impermeable at the top), Eq. (2) can be solved analyticallyto provide insight into the potential magnitude of pressure changes and accompanying fluid flow rates as the material deforms in response to externally applied shearing strains. The position-dependent order of magnitude change in excess pore (fluid) presure in a layer of thickness $H$ is:

$$
p=\frac{R \dot{c}\left(H^{2}-y^{2}\right)}{2 k \theta}
$$

where $k$ is the matrix permeability and $\theta$ in this case is the ppv matrix strength (taken arbitairly as $10^{9} \mathrm{~Pa}$ ). Finally, the upwelling $(u)$ rate is:

$$
u=\frac{e H G}{\theta}=\frac{s^{-1} m P a}{P a}=m s^{-1}
$$

where $G$ is the ppv shear modulus, obtained from ab-initio calculations (Stackhouse et al., 2005).

\section{REFERENCES}

Asahara, Y., D.J. Frost and D.C. Rubie (2007) Partitioning of FeO between magnesiowüstite and liquid iron at high pressures and temperatures: Implications for the composition of the Earth's outer core Earth Planet. Sci. Lett., 257, 435-449.

Alfe, D., Price, G.D., and M. J. Gillan, M.J. (2002) Composition and temperature of the Earth's core constrained by combining $a b$ initio calculations and seismic data, Earth Planet. Sci. Lett., 195, 91-98.

Bloxham, J., S Zatman, and M Dumberry (2002) The origin of geomagnetic jerks. Nature, 420, $65-68$.

Boyet M. and Carlson, R.W. (2005) ${ }^{142} \mathrm{Nd}$ Evidence for Early (4.53 Ga) Global differentiation of the silicate Earth, Science, 309, 576-580.

Brandon, A.D. and Walker, R.J. (2005) The debate over core-mantle interaction, Earth Planet. Sci. Lett. 232, 211 - 225. 
Brandon, A. D., Walker, R.J., Morgan, J. W., Norman, M.D. and Prichard, H. M., (1998) Coupled ${ }^{186}$ Os and ${ }^{187}$ Os evidence for core-mantle interaction, Science vol. 280, 1570-1573.

Brandon, A. D., R. J. Walker, I. S. Puchtel, H. Becker, M. Humayun, and S. Revillon (2003) ${ }^{186} \mathrm{Os}^{-187}$ Os systematics of Gorgona Island komatiites: Implications for early growth of the inner core, Earth Planet. Sci. Lett., 206, 411-426

Brewster, M.Q., (1992) Thermal Radiative Transfer and Properties: New York, John Wiley and Sons, Inc., 543 p.

Bruhn, D., Groebner, N., Kohlstedt, D.L. (2000) An interconnected network of core forming melts produced by shear deformation, Nature 403, $883-886$.

Buffett, B. A. and Wenk, H. R. (2001) Texturing the Earths's inner core by Maxwell Stresses, Nature, 413, 60-63.

Buffett, B. A., E. J. Garnero, and R. Jeanolz, (2000) Sediments at the top of the Earth's core, Science, 290, 1338-1342.

Cadek, O. and Fleitout, L. (2006) Effect of lateral viscosity variations in the core mantle boundary region on predictions of the long wavelength geoid. Stud. Geophys. Geod., 50, 217-232.

Connolly, J.A.D. and Podladchikov, Y. (1998) Compact-driven fluid low in viscoelastic rock, Geodinimica Acta (Paris), 11, 2-3, 55-84.

Connolly, J.A.D., Gerya, T. and Yuen, D.A. (2005) Initiation of thermochemical plumes from the post-perovskite layer. Eos. Trans. AGU 86 (18) Jt. Assembly Suppl., Abs. U 31 A-06.

Davies, G. F. (1999). Dynamic Earth: Plates, Plumes and Mantle Convection, Cambridge University Press, UK, pp. 455.

Dubuffet, F. Yuen, D. A. and Rainey, E.S.G., (2002) Controlling thermal chaos in the mantle by positive feedback from radiative thermal conductivity. Nonlinear Processes in Geophysics 9: $311-323$.

Earle P. S. and Shearer, P. M., (1997) Observations of PKKP precursors used to estimate smallscale topography on the core-manlte boundary. Science, 277, 667-670

Fujisawa, H., Fujii, N,. Mizutani, H., Kanamori, H., and Akimoto, S., (1968) Thermal Diffusivity of $\mathrm{Mg} 2 \mathrm{SiO} 4, \mathrm{Fe} 2 \mathrm{SiO} 4$, and $\mathrm{NaCl}$ at High Pressures and Temperatures, J. Geophys. Res., v. 75, p. 4727-4733.

Garnero, E. J. (2000) Heterogeneities in the lowermost mantle, Annu. Rev. Earth Planet Sci. 28, 509-537.

Gerya, T. V., Connolly, J.A., Yuen, D.A., Oganov, A (2006) Multiple scale plume dynamics from the post-perovskite layer: Insight from internally consistent petrological - thermomechanical modeling. International workshop on the post-perovskite transition in the Earth's deep mantle. Tokyo Institute of Technology, Japan, October 3-4, 2005.

Gibbons, S. J. and Gubbins, D., (2000) Convection in the Earth's core driven by lateral variations in the core-mantle boundary heat flux, Geophys. $J$. Int., 142, 631-642.

Gorczyk, W., Gerya, T. V., Connolly, J.A., Yuen, D.A., (2007). Growth and mixing dynamics of mantle wedge plumes. Geology (in press).

Hansen, U. and Yuen, D.A. (2000) Extended-Boussinesq thermal-chemical convection with moving heat sources and variable viscosity, Earth Planet. Sci. Lett., 176, 401-411.

Hapke, B. (1993). Theory of Reflectance and Emittance Spectroscopy. Cambridge University Press, Cambridge.

Hernlund, J.W., Thomas, C., and Tackley, P.J., 2005, A doubling of the postperovskite phase boundary and structure of the Earth's lowermost mantle: Nature, v. 434, p. 882-886.

Hide, R., Clayton, R.W., Hager, B.H., Speith, M.A. and Voorhies, C.V. (1993) Topographic core-mantle coupling and fluctuations in the Earth's rotation, Geophys. Mono., 76, 107-120. RTOP 579-31-07.

Hofmeister, A.M., 1999, Mantle values of thermal conductivity and the geotherm from phonon lifetimes: Science, v. 283, p. 1699-1706.

Hofmeister, A.M., (2005) The dependence of diffusive radiative transfer on grain-size, temperature, and Fe-content: implications for mantle processes. Journal of Geodynamics, 40, 51-72.

Hofmeister, A.M. (2006) Thermal conductivity of Earth's deepest Mantle. Superplume: Beyond Plate Tectonics (D.A. Yuen, S. Maruyama, S.I. Karato, and B.F. Windley, eds.) Spinger-Verlag. 540 pgs.

Hofmeister, A. M., P. A. Giesting, B. Wopenka, G. D. Gwanmesia, and B. L. Jolliff (2004) Vibrational spectroscopy of pyrope-majorite garnets: structure and order. American Mineralogist 89, 132-146.
Humayun, M., Qin, L., and Norman, M. D., (2004) Geochemical evidence for excess iron in the mantle beneath Hawaii, Science, 306, 91-94.

Ishii, M. and Tromp, J. (1999) Normal-mode and free-air gravity constraints on lateral variations in velocity and density of Earth's mantle, Science 285, 1231-1236.

Kanda, R. V. S., and Stevenson, D.J., (2006), Suction mechanism for iron entrainment into the lower mantle, Geophys. Res. Lett., v. 33, ArtNo. L02310.

Karato, S., (1998a) Some remarks on the origin of seismic anisotropy in the D" layer Earth Planets Space, 50, 1019-1028.

Karato, S., (1998b) Seismic anisotropy in the deep mantle, boundary layers and the geometry of mantle, Pure and Applied. Geophys., 151, 565-587.

Karato, S., (1999) Seismic anisotropy of the Earth's inner core resulting from flow induced by Maxwell stresses. Nature, v. 402, 871-873.

Kaufmann, R., and Freedman, W.J. (2002) Universe (W.H. Freeman, New York) $800 \mathrm{pp}$.

Kellog, L.H., Hager, B. H. and van der Hilst, R.D. (1999). Compositional stratification in the deep mantle. Science v. 283, 1881-1884.

Knittle E., and Jeanloz, R. (1989) Simulating the core-mantle boundary: an experimental study of high-pressure reactions between silicates and liquid iron. Geophys. Res. Lett. v. 16, 609- 612.

Knittle E., and Jeanloz, R. (1991) Earth's core-mantle boundary: results of experiments at high pressures and temperatures Science 251, 438-444.

Koenders, M.A., and Petford, N. (2000) Quantitative analysis and scaling of sheared granitic magmas, Geophys. Res. Lett, 27, 1231-4.

Koenders, M.A. and Petford N. (2005) Seepage and consolidation phenomena in a porous deforming layer II, Geophys. J. Int 163, 385-402.

Koenders, M.A. and Petford N. (2007) Shear-induced pressure changes and seepage phenomena in a deforming porous layer III, Geophys. J. Int (in press).

Kuang, W. (1999) Force balances and convective state in the Earth's core. , Phys. Earth. Planet. Interior, 116, 65-79.

Lay, T., Garnero, E. J. and Williams Q. (2004) Partial melting in a thermochemical boundary layer at the base of the mantle, Phys. Earth. Planet. Interior, 146, 441-467.

Lin, J.-F., Struzhkin, V.V., Jacobsen, S.D., Hu, M.Y., Chow, P., Kung, J., Liu, H., Mao, H.-K. and Hemley, R.J. (2005) Spin transition of iron in magnesiowuestite in the Earth's lower mantle, Nature, 436, 377-380.

Loper, D. E. and T. Lay, (1995) The core-mantle boundary region, J. Geophys. Res., 100, 6397-6420.

Mao, W., G. Shen, V. Prakapenka, Y. Meng, A. Campbell, D. Heinz, J. Shu, R. Hemley, and H. K. Mao, (2004) Ferromagnesian postperovskite silicates in the D" layer of the Earth, Proc. Natl. Acad. Sci., 101, 15867-15869.

Matyska, C. and Yuen, D. A. (2005) The importance of radiative heat transfer on superplumes in the lower mantle with the new post-perovskite phase change. Earth Planet. Sci. Lett. 234, 71-81.

Matyska, C. and Yuen, D. A. (2006) Lower mantle dynamics with the postperovskite phase change, radiative thermal conductivity, temperature- and depth-dependent viscosity: Phys. Earth Planet. Inter., v. 154, p. 196-207.

Matyska, C., Moser, J., Yuen, D.A., (1994) The potential influence of radiative heat transfer on the formation of megaplumes in the lower mantle. Earth Planet. Sci. Lett. 125, 255-266.

McKenzie, D., (1984) The generation and compaction of partially molten rock, J. Petrol. 25, 713-765.

McNamara, A. K, van Keken, P.E. and Karato, S., (2002). Development of anisotropic structure in the Earth's lower mantle by solid-state convection, Nature, v. 416, 310-314.

Monnereau, M. and Yuen, D. A. (2007) Post-perovskite phase change and lower-mantle dynamics. PNAS Proceedings National Academy of Science.

Montelli, R., G. Nolet, F. Dahlen, G. Masters, E. Engdahl, S.-H. Hung, (2004) Finite frequency tomography reveals a variety of plumes in the mantle, Science 303, 338-343.

Murakami, M., Hirose, K., Kawamura, K., Sata, N. and Ohishi, Y. (2004) Post-Perovskite Phase Transition in MgSiO3 Science, v. 304, 854-855.

Nakagawa, T. and P.J. Tackley, (2004) Effects of a perovskite-post perovskite phase change near core-mantle boundary in compressible mantle convection, Geophys. Res. Lett., v. 31, Art. No. L16611.

Nakagawa, T. and P.J. Tackley, (2006) Three-dimensional structures and dynamics in the deep mantle: Effects of post-perovskite phase change and deep mantle layering: Geophys. Res. Lett., v. 33, Art. No. L12S11. 
Nolet, G., S-I. Karato, R. Montelli (2006) Plume fluxes from seismic tomography. Earth Planet. Sci. Lett. 248, $685-699$.

Oganov, A.R., and Ono, S. (2004) Theoretical and experimental evidence for a post-perovskite phase of $\mathrm{MgSiO} 3$ in Earth's D" layer, Nature 430 , $445-448$.

Ohtani, E., and M. Maeda (2001), Density of basaltic melt at high pressure and stability of the melt at the base of the lower mantle, Earth Planet. Sci. Lett., 193, $69-75$.

Olson, P., (2003) Thermal interaction of the core and mantle, in Earth's Core and Lower Mantle, edited by C. A. Jones, A. M. Soward, and K. Zhang, pp. 1-29, Taylor and Francis, London

Panning, M. and Romanowicz, B. (2004) Inferences on flow at the base of the mantle based on seismic anisotropy, Science 303, 351-353.

Petford, N. and Koenders, M., (2003) Shear-induced pressure changes and seepage phenomena In a deforming porous layer-I Geophys. J. Int. 155, 857-869.

Petford, N., Yuen, D., Rushmer, T., Brodholt, J., Stackhouse, S., (2005a) Shear-induced material transfer across the core-mantle boundary aided by the post-perovskite phase transition Earth Planets Space, 57, 459-464.

Petford, N. Yuen, D., and Rushmer, T., (2005b) Microscale deformation of (post) perovskite dominated sediment in the uppermost outer core. Eos. Trans. AGU 86 (18) Jt. Assembly Suppl., Abs. U32A-02.

Petford, N., Rushmer, T., Yuen, D., and Walte, N. (2006) Can deformation help us explore the chemical nature of the core-mantle boundary? Eos. Trans. AGU 87 (18), Abs. UA41-0802.

Poirier, J-P (1995) Core-infiltrated mantle and the nature of the D" layer, J. Geomag. Geoelectr., 45, 1221-1227.

Reynolds, O., (1885) On the dilatancy of media composed of rigid particles in contact, Phil. Mag., 20, 469-481.

Romanowicz, B., Y. Gung (2002) Superplumes from the core-mantle boundary to the lithosphere: implications for heat flux, Science 296, 513-516.

Rost, S., E. J. Garnero, Q. Williams, M. Manga (2005) Seismological constraints on a possible plume root at the core-mantle boundary Nature, 435 , 666-669.

Rowe, P. W., The stress dilatancy of media composed of rigid particles in contact, with experimental illustrations. Proc. R. Soc. London, 269, 500-527, 1962.

Rushmer, T., Minarik, W. G., and Taylor, G.J., (2000) Physical processes of core formation. In: Origin of the Earth and Moon. Eds. K Righter and R. Canup. Lunar Planetary Institute and University of Arizona Publishers. pp. 227-245

Rushmer, T., Petford, N., Humayun, M., and Campbell, A. J., (2005) Fe-liquid segregation in deforming planetesimals: coupling core forming compositions with transport phenomena. Earth Planet. Sci. Lett. vol. 239, 185-202

Sakai T., T. Kondo, E. Ohtani, H. Terasaki, N. Endo, T. Kuba, T. Suzuki, T. Kikegawa (2006), Interaction between iron and post-perovskite at coremantle boundary and core signature in plume source region, Geophys. Res. Lett., 33, L15317, doi:10.1029/2006GL026868.

Schubert, G., D. Yuen, D.Turcotte (1975) Role of phase transitions in a dynamic mantle, Geophys. J. R. Astr. Soc. 42, 705-735.

Secco, R. A., G.E. LeBlanc, H. Yang, J. N.Seibel, (1998) High pressure viscosity of an Fe-S liquid: experimentally derived of the viscosity of the outer earth's core. In: M. H. Manghanani and T. Yagi (Eds.) Properties of Earth and Planetary Materials at High Pressure and Temperature, $A G U$ Geophysical Monograph 101, pp. 495-506.

Shannon, M.C. and C.B. Agee, (1996) High pressure constraints on percolative core formation, Geophys. Res. Lett. 23, 2717-2720.

Shim, S-H (2005). Stability of MgSiO 3 Perovskite in the Lower Mantle; Geophysical Monograph Series, "Earth's Deep Mantle: Structure,
Composition, and Evolution"; Rob D. van der Hilst, Jay Bass, Jan Matas, Jeannot Trampert, (Eds); 160, pp. 263-285

Sleep, N., (1990) Hotspots and mantle plumes: some phenomenology, J. Geophys. Res. 95 (1990) 6715-6736.

Spera, F. J., Yuen, D.A., G. Giles, (2006) Trade-offs in chemical and thermal variations in the post-perovskite phase transition: Mixed phase regions in the deep lower mantle? Physics Earth Planet Inter., (in press)

Stackhouse, S., J. P. Brodholt, J. Wookey, J-M. Kendall, and Price, D., (2005) The effect of temperature on the seismic anisotropy of the perovskite and post-perovskite polymorphs of $\mathrm{MgSiO}_{3}$, Earth Planet. Sci. Lett., 230, 1-10.

Stevenson, D. J., (1990), Fluid dynamics of core formation. In: The Origin of the Earth, (H. Newsom and J. H. Jones, eds.) Univ. Oxford Press, London. pp. 231-249.

Stevenson, D., (2003) Material transfer across the core-mantle boundary, Geophys. Res. Abstracts, 5, 03290.

Takafuji N., K. Hirose, M. Mitome, Y. Bando (2005) Solubilities of O and Si in liquid iron in equilibrium with $(\mathrm{Mg}, \mathrm{Fe}) \mathrm{SiO} 3$ perovskite and the light elements in the core, Geophys. Res. Lett., 32, L06313, doi:10.1029/ 2005GL022773.

Tateno, S., K. Hirose, N. Sata and Y. Ohishi (2007) Solubility of FeO in $(\mathrm{Mg}, \mathrm{Fe}) \mathrm{SiO} 3$ perovskite and the post-perovskite phase transition, Physics of the Earth and Planetary Interiors 160, 319-325.

Terzaghi, K., 1925. Erdbaumechanik auf bodenphysikalischer Grundlage. Deuticke, Vienna, 399 pp.

Tsuchiya, T., J. Tsuchiya, K. Umemoto, and R. M. Wentzcovitch, (2004) Phase transition in $\mathrm{MgSiO} 3$ perovskite in the Earth's lower mantle, Earth Planet. Sci. Lett., 224, 241-248.

Trampert, J., Deschamps, F., Resovsky, J and Yuen, D. A. (2004) Probablistic tomography maps of chemical heterogeneities in the lower mantle, Science, Vol. 306. no. 5697, pp. $853-856$.

Vasilyev, O.V., Podladchikov, Y.Y, and D.A. Yuen, (1998) Modeling of compaction driven flow in poro-viscoelastic medium using adaptive wavelet collocation method, Geophys. Res. Lett. 25, No. 17, p. 3239-3243,

Vasilyev, O.V., (2003) Solving multi-dimensional evolution problems with localized structures using second generation wavelets, Int. J. Comp. Fluid Dyn., 17, 151-168.

Wang, Y. and Wen, I. (2004) Mapping the geometry and geographic distribution of a very low velocity province at the base of the Earth's mantle, J. Geophys. Res. 109, B10305, doi:10.1029/2003JB002674.

Walker, R.J. and Walker, D. (2005) Does the core leak? EOS, v. 86, n. 25 , June 2005.

Walker, R.J., Morgan, J.W., and Horan, M.F. (1995) ${ }^{187}$ Os enrichment in some mantle plume sources: Evidence for core-mantle interaction?, Science 269 819-822.

Whaler, K.A. (1986) Geomagnetic evidence for fluid upwelling at the coremantle boundary Geophys. J. of the Royal Astronomical Soc. 86:22, 563-588.

Williams Q. and Garnero, E. J. (1996) Seismic evidence for partial melt at the base of the Earth's mantle, Science, v. 273, 1528-1530.

Yamazaki, D., Yoshino, T., Ohfuji, H., ando, J-I, Yoneda, A. (2006) Origin of seismic anisotropy in the D" layer inferred from shear deformation experiments on post-perovskite phase. Earth Planets and Space, 252, 372-378.

Yanagawa, T.K.B., Nakada, M. and Yuen, D.A. (2005) Influence of lattice thermal conductivity on thermal convection with strongly temperaturedependent viscosity, Earth Planets and Space, Vol. 57, No. 1, 15-28.

Yuen D. A., U. Hansen, W. Zhao, A. P. Vincent, A. V. Malevsky (1993) Hard turburlent thermal convection and thermal evolution of the mantle. $J$. of Geophys. Res., Vol. 98, No. E3, Pages 5355-5373, 1993

Yuen, D. A., Matyska, C., Cadek, O.and Kameyama, M. (2007) The dynamical influences from physical properties from the lower mantle and postperovskite transition. AGU Monograph, this volume. 